\title{
STATISTICAL OPTIMIZATION AND EVALUATION OF ETHOSOMAL MICONAZOLE NITRATE SUSPENSION
}

\section{N. MADHURI*, N. TEJASWINI, MEENAL PATEL, P. JYOTHI, K. JYOTHSNA, P. N. MALLIKARJUN}

Vignan Institute of Pharmaceutical Technology, Beside VSEZ, Duvvada, Visakhapatnam 530049

Email: madhurinaveti@gmail.com

Received: 03 Sep 2021, Revised and Accepted: 26 Oct 2021

\section{ABSTRACT}

Objective: The objectives of the present study were to optimize and evaluate the ethosomal suspension of miconazole nitrate for the treatment of local and systemic fungal infections.

Methods: Miconazole topical formulation is prepared for better patient compliance and to reduce the dose of a drug. Miconazole nitrate ethosomes were prepared by the cold method using factorial designing with Ethanol(X1), IPA(Isopropyl alcohol)(X2), and Lecithin(X3) as Independent variables and \% EE(Entrapment efficiency)(Y1) and \% DR(drug release at 8th $\mathrm{h}$ )(Y2) was selected as responses.

Results: The results obtained in the design showed that there was no significant interaction among factors. The lecithin concentration had a positive response on \% EE, while ethanol concentration and IPA had a positive effect. For \% DR, Ethanol, and IPA showed a positive effect and Lecithin had a negative response. The formulation EM22 (3 ml X1,3 ml X2 and $300 \mathrm{mg}$ of X3) characterized by high \% EE(77.3 \%) and optimum \% DR(94.2\%) and formulation EM6 (2 ml X1,2 ml X2 and $100 \mathrm{mg}$ of X3) characterized by high \% DR(97.32\%) and optimum \% EE (74.8 \%). EM22 was incorporated in the gel as it is showing more entrapment efficiency and compared with the marketed product for drug release.

Conclusion: From the result, it was concluded that formulated ethosomal suspension and optimized gel have more drug release than marketed formulation so that formulated suspension can be used for the preparation of antifungal gels, creams, ointments for sustained release.

Keywords: Ethosomes, Miconazole, Ethanol, Isopropyl alcohol, Antifungal, Cold method, Optimization

(C) 2022 The Authors. Published by Innovare Academic Sciences Pvt Ltd. This is an open access article under the CC BY license (https://creativecommons.org/licenses/by/4.0/) DOI: https://dx.doi.org/10.22159/ijap.2022v14i1.43048. Journal homepage: https://innovareacademics.in/journals/index.php/ijap

\section{INTRODUCTION}

Ethosomes are vesicle lipid vesicle carriers that contain phospholipids and have a high concentration of ethanol and water. It is a system that has important characteristics related to the ability to increase skin permeability [1]. The size of ethosomes will be in the range of tens of nanometers to microns $(\mu)$ which have a smaller size related to liposomes [2-4].

Those can efficiently entrap various molecules, like lipophilic, lipophilic, and amphiphilic molecules. It can be explained by the high degree of lamellarity and the presence of ethanol in the vesicles, which allows better solubility of many drugs. Moreover, ethosomal formulations possess greater entrapment capability than liposome1. One of the important features of ethosomes is due to their soft and flexible nature; they can penetrate the skin and allow enhanced delivery of various active agents to deeper strata of the skin or enhanced systemic circulation compared to the conventional liposome or hydroethanolic solutions [5]. The better permeability of those carriers may be due to the synergistic mechanism between a high concentration of ethanol, phospholipids vesicles, and skin lipids. Ethosomes are biocompatible and biodegradable drug delivery systems [6]. Ethanol interacts with lipid molecules in the polar head group region resulting in increasing fluidity and may finally lead to increase membrane permeability. In addition, it may provide the vesicles with soft flexible characteristics, which will improve the drug distribution ability in the stratum corneum lipids of the skin, and also formulations provide sustained delivery of drugs where ethosomes act as reservoir system for continues delivery of drugs $[6,7]$. The release of a drug could be the result of a fusion of those with skin lipids and drug release at various points along the penetration pathway [1]. Many studies have used those as a carrier system of drug delivery for transdermal or topical administration. It has been reported to improve various drug deliveries both in vivo and in vitro skin, such as Testosterone, Cannabidiol, Buspirone hydrochloride, Erythromycin, Ammonium glycyrrhizinate, Lamivudine, and 5-aminolevulinic acid [4, 5, 8].

\section{MATERIALS AND METHODS}

\section{Materials}

The materials which are used in the preparation of ethosomes are Miconazole nitrate (Natco Pvt Ltd, Hyderabad, India.) Ethanol (SD Fine Chem Pvt Mumbai, India.), Cholesterol (Qualigens), Lecithin (Prepared in the laboratory), Propylene glycol (SD Fine Chem Pvt Mumbai, India), Isopropyl alcohol (SD Fine Chem Pvt Mumbai, India.) Water, Carbopol 934 (Corel Pharma Chem, Ahmedabad, India), Triethanolamine (SD Fine Chem Pvt Mumbai, India) and Methanol (SD Fine Chem Pvt Mumbai, India.). FTIR Spectrophotometer (BRUKER FTIR INVINIO, Japan), UV Spectrophotometer (LAB INDIA UV-VIS spectrophotometer), PH meter (Systonics India Ltd. India), Magnetic stirrer (Elite Scientific and Equipment, India), Franz diffusion cell (Locally fabricated), Ultra Sonicator (Spino tech Pvt. Ltd), Optical Microscope (MicroLabs, India). Glassware (Borosilicate), Hot air oven (Elite Scientific and Equipment, India), Electric balance (Elite Scientific and Equipment, India).

\section{Preparation of egg lecithin}

Eight egg yolks were collected and were put in a beaker. To it, $50 \mathrm{ml}$ of acetone was added and precipitation takes place. It was stirred with the help of a glass rod for some time. The precipitate was placed in the centrifuge tube. Centrifuge tubes were kept in the centrifugation machine for five minutes and it was rotated at 4000 rpm. The supernatant liquid was separated from the precipitate and was kept in the beaker. The precipitate was collected and it was washed with acetone. This step was repeated 2-3 times for filtration purposes. After filtration, the precipitate appears as white colored substance and filtrate as colorless. A mixture of chloroform and ethanol was added to the precipitate in the ratio of 2:1 for extraction purposes and it was left for $3 \mathrm{~h}$. The precipitate was filtered and the filtrate was collected and was transferred to a Petri dish. The solvent was evaporated and the crude lecithin was extracted. The extracted crude lecithin was dissolved in $10 \mathrm{ml}$ petroleum ether and to it, only $50 \mathrm{ml}$ acetone was added to the precipitate and was kept for some time. Then lecithin was settled down in the Petri dish and the liquid 
was decanted. The sticky substance which was settled down in the Petri dish was the egg lecithin [9].

\section{Formulation of ethosomes using the cold method}

Ethosomes were prepared by the cold method using cholesterol, egg lecithin, propylene glycol, ethanol, Isopropyl alcohol, and water. In this method, phospholipids and $100 \mathrm{mg}$ of the drug were dissolved in ethanol/IPA(Isopropyl alcohol) in a covered vessel at room temperature by vigorous stirring in a magnetic stirrer for $20 \mathrm{~min}$. After 20 min propylene glycol $(1 \mathrm{ml})$ was added at a time to avoid evaporation of ethanol in a closed vessel and allowed to stir for 10 min. The water was heated to $40{ }^{\circ} \mathrm{C}$ in a separate vessel and was added to the above mixture. The mixture was stirred for $10 \mathrm{~min}$ at $700 \mathrm{rpm}$ in a covered vessel. The size reduction of ethosomal formulation was done by sonication for $20 \mathrm{~min}$ or extrusion method and finally, the formulation was stored under the refrigerator. Optimized formulation was incorporated in the carpool 934 to form ethosomal gel (EG) [10].

\section{Experimental design}

A factorial design was utilized in the present study. Several studies revealed that the optimized lipid concentration, ethanol, and IPA concentration play a notable role in entrapment efficiency (EE) of the drug and \% drug release (DR) from ethosomal formulation. Here an attempt was made to study the interactive effect of all these variables on ethosome formulation characteristics. The design layout and coded value of the independent factor are shown in table 1 . The lipid concentration, ethanol, and IPA concentration were selected as independent variables. The \% EE and \% DR of ethosomal formulation were selected as dependent variables. Design-Expert version 12 was used for the generation and evaluation of the statistical experimental design. An ANOVA test was performed to evaluate the level of significance of the tested factors on the selected responses as well as the interactions between these factors. The application of regression analysis is important to check that our independent variables have a significant effect on our response or not. Surface response plots were also presented to graphically represent the effect of the independent variables on the \%drug release and \%entrapment efficiency.

Composition of different coded values in the factorial design of miconazole ethosomes

\section{Independent variables}

Coded Values X1: A [Ethanol] at two levels ( 2 and $3 \mathrm{ml}$ )

X2: B [IPA] at two levels (2 and $3 \mathrm{ml}$ )

\section{X3: C [Lecithin] at six levels $(100,150,200,250,300$ and $400 \mathrm{mg})$}

\section{Drug entrapment efficiency}

The entrapment efficiency of Miconazole nitrate ethosomal vesicles was determined by centrifugation. The vesicles were separated in a high-speed cooling centrifuge at $3000 \mathrm{rpm}$ for $1 \mathrm{~h} 30 \mathrm{~min}$. The sediment and supernatant liquids were separated, amount of drug in the sediment was determined by lysing the vesicles using methanol. It was then diluted appropriately and estimated using a UV visible spectrophotometer at $272 \mathrm{~nm}$ [11].

$$
\text { Percent Entrapment }=\frac{\text { Amount of drug Entrapped }}{\text { Amount of drug added }} \times 100
$$

\section{In vitro drug release studies}

The in vitro drug release studies of miconazole nitrate from ethosomal formulation were studied using Franz diffusion cell. The in vitro diffusion of the drug was performed through one end of the hollow glass tube. This acted as a donor compartment. $10 \mathrm{ml}$ of Phosphate buffer saline $6.8 \mathrm{pH}$ was taken in a beaker which was used as a receptor compartment. A known quantity was spread uniformly on the egg membrane. The donor compartment was kept in contact with the receptor compartment and the temperature was maintained at $37 \pm 0.5^{\circ} \mathrm{C}$. The solutions of the receptor side were stirred by a small magnetic bead and were rotated at a constant speed. At predetermined time intervals, samples were withdrawn and replaced by $5 \mathrm{ml}$ of PBS. The drug concentrations in the aliquot were analyzed for drug content using a UV spectrophotometer at $272 \mathrm{~nm}$ against appropriate blank [12].

\section{Optical microscope observation}

The ethosomal dispersion was spread on the glass slide using a glass rod $[8,10,13]$ Formation of multilamellar vesicles was confirmed by examining the ethosomal suspension under an optical microscope with a magnification of $40 \mathrm{X}$ and 10X. Photographs of vesicles were taken using a Samsung galaxy camera [14].

\section{Preparation of gel}

Gel base was prepared by dispersing 1\% w/v Carbopol 934 in distilled water. The polymer was soaked in water for $2 \mathrm{~h}$ and then dispersed in distilled water using a magnetic stirrer to obtain a homogeneous gel adjusting the $\mathrm{pH}$ by using triethanolamine solution. For the preparation of ethosomal gel, the ethosomal suspension was centrifuged at $14000 \mathrm{rpm}$ for $20 \mathrm{~min}$, and the obtained suspension was incorporated into the prepared gel base [15].

\section{pH measurement}

The $\mathrm{pH}$ measurements of the formulations were carried out using a $\mathrm{pH}$ meter by dipping the glass electrode completely into the gel formulation to cover the electrode [16].

\section{Drug content}

The drug content was estimated spectrophotometrically $50 \mathrm{mg}$ equivalent of optimized ethosomal gel was taken and dissolved in methanol and filtered. The volume was made up to $10 \mathrm{ml}$ with methanol. The resultant solution was suitably diluted with methanol and absorbance was measured at $272 \mathrm{~nm}$ [17].

\section{Viscosity}

The measurement of the viscosity of the prepared gel was done using Brookfield digital viscometer. The viscosity was measured using spindle no. 6 at $10 \mathrm{rpm}$ and $25^{\circ} \mathrm{C}$. A sufficient quantity of gel was filled in an appropriate wide mouth container. The gel was filled in the wide mouth container in such a way that it should sufficiently allow to dip the spindle of the Viscometer. Samples of the gels were allowed to settle over $30 \mathrm{~min}$ at the constant temperature $(25 \pm / 10$ ${ }^{\circ} \mathrm{C}$ ) before the measurements [17].

\section{Spreadability}

The spreadability of the gel formulation was determined $48 \mathrm{~h}$ after preparation by measuring the spreading diameter of $10 \mathrm{~g}$ of the gel between two glass plates after $1 \mathrm{~min}$. The mass of the upper plate was standardized at $20 \mathrm{~g}$, placing slides one above the other and counting the time taken for 2nd slide to slip out from another slide. Lesser the less time is taken for the separation of two slides, the better the spreadability. It is determined by the formula given below [17].

$$
\text { Spreadability }=m \cdot \frac{1}{t}
$$

Where, $\mathrm{S}=$ Spreadability (g. $\mathrm{cm} / \mathrm{s}), \mathrm{m}=$ weight tied to the upper slide $(20 \mathrm{~g}), \mathrm{l}=$ length of glass slide $(6 \mathrm{cms}), \mathrm{t}=$ time taken is $\mathrm{s}$.

\section{In vitro drug release}

The in vitro drug release studies of optimized ethosomal gel and marketed microgel cream were studied using Franz diffusion cell (same as above) [12].

\section{Stability studies}

The stability studies were performed at $40{ }^{\circ} \mathrm{C} \pm 2{ }^{\circ} \mathrm{C}$; samples were analyzed at periodic time intervals for 3 mo for the estimation of $\mathrm{pH}$, viscosity, and drug content [15].

\section{RESULTS AND DISCUSSION}

\section{Analysis of factorial design}

Preliminary formulation screening data was used for defining design space in factorial designs shown in table 1 for an optimization study by comparing reference [18]. Percent entrapment efficiency and Drug release were selected as response parameters, as they play an important role in providing the efficacy of the formulation. 
Table 1: Factorial design matrix of miconazole nitrate ethosomes with evaluation parameters

\begin{tabular}{|c|c|c|c|c|c|}
\hline & Factor 1 & Factor 2 & Factor 3 & Response 1 & Response 2 \\
\hline Run & X1:Ethanol & X2:IPA & X3:Lecithin & Y1:EE & Y2:DR \\
\hline Units & $\mathrm{ml}$ & ml & mg & $\%$ & $\%$ \\
\hline EM1 & 3 & 3 & 100 & 75.1 & 94.36 \\
\hline EM 2 & 2 & 3 & 150 & 75.3 & 96.25 \\
\hline EM 3 & 2 & 2 & 250 & 76.5 & 95.9 \\
\hline EM 4 & 2 & 2 & 400 & 77.1 & 92 \\
\hline EM 5 & 2 & 3 & 300 & 76.3 & 95 \\
\hline EM 6 & 2 & 2 & 100 & 74.8 & 97.32 \\
\hline EM 7 & 3 & 3 & 200 & 76.5 & 96.74 \\
\hline EM 8 & 2 & 3 & 250 & 76.5 & 95.36 \\
\hline EM 9 & 2 & 2 & 200 & 76.3 & 96.9 \\
\hline EM 10 & 3 & 2 & 250 & 76.1 & 95.32 \\
\hline EM 11 & 3 & 2 & 400 & 77.1 & 91.23 \\
\hline EM 12 & 3 & 3 & 150 & 75.4 & 97.11 \\
\hline EM 13 & 3 & 3 & 250 & 76.2 & 95.12 \\
\hline EM 14 & 2 & 3 & 400 & 77 & 91 \\
\hline EM 15 & 3 & 2 & 200 & 76.4 & 96.23 \\
\hline EM 16 & 3 & 2 & 150 & 76.2 & 97 \\
\hline EM 17 & 2 & 3 & 100 & 74.9 & 96.5 \\
\hline EM 18 & 3 & 2 & 300 & 77.2 & 94.3 \\
\hline EM 19 & 3 & 2 & 100 & 75.2 & 96.35 \\
\hline EM 20 & 2 & 3 & 200 & 76.4 & 96.82 \\
\hline EM 21 & 2 & 2 & 150 & 75.2 & 97.12 \\
\hline EM 22 & 3 & 3 & 300 & 77.3 & 94.2 \\
\hline EM 23 & 2 & 2 & 300 & 76.2 & 94.8 \\
\hline EM 24 & 3 & 3 & 400 & 77.2 & 90.23 \\
\hline
\end{tabular}

Table 2: Statistical and regression analysis results for all responses

\begin{tabular}{|c|c|c|c|c|}
\hline & Y1Y1 & & Y2Y2 & \\
\hline Source & F-values & P-values & F-values & P-values \\
\hline Model & 14.91 & $<0.0001$ & 37.21 & $<0.0001$ \\
\hline $\mathrm{X} 1$ & 3.89 & 0.0662 & 5.11 & 0.0380 \\
\hline $\mathrm{X} 2$ & 0.0025 & 0.9605 & 3.57 & 0.0771 \\
\hline X3 & 92.52 & $<0.0001$ & 202.442 & $<0.0001$ \\
\hline Lack of fit & $<0.005$ & $<0.005$ & $<0.005$ & $<0.005$ \\
\hline \multicolumn{5}{|l|}{$\mathrm{R}^{2}$ analysis } \\
\hline $\mathrm{R} 2$ & 0.8671 & & 0.9421 & \\
\hline Adjusted R2 & 0.8089 & & 0.9168 & \\
\hline Predicted R2 & 0.7532 & & 0.8385 & \\
\hline Adequate Precision & 11.8571 & & 18.9635 & \\
\hline Model & Quadratic & & Quadratic & \\
\hline Remark & Suggested & & Suggested & \\
\hline
\end{tabular}

$\mathrm{X} 1=$ Ethanol $(\mathrm{ml}), \mathrm{X} 2$ = IPA(ml), X3=Lecithin $(\mathrm{mg}), \mathrm{Y} 1=\%$ Entrapment efficiency, Y2=\% Drug release

\section{Drug entrapment efficiency (\%EE)}

\section{Effect of permeation enhancer on \%EE}

The percentage of entrapped drugs in the prepared ethosome was calculated and represented as \% of EE that ranged between $74.8 \%$ and $77.2 \%$ as presented in table 1 . It was observed that a little increment in the EE when the independent variable X1, X2 at a higher level (EM1, EM7, EM12, EM13, EM22, and EM24) compared to the lower level (EM3, EM4, EM6, EM9, EM21, and EM23). When the formulation containing $\mathrm{X} 1$ at higher level (EM10, EM11,EM15,EM16,EM18 and EM19) showed improved EE compared to X2 at higher level (EM2,EM5,EM8,EM14,EM17 and EM20).

\section{Effect of lecithin on \% EE}

Formulation containing level $100 \mathrm{mg}$ (EM1,EM6,EM17 and EM19) showed EE of $75.1 \%, 74.8 \%, 74.9 \%$ and $75.2 \%$ respectively and level $400 \mathrm{mg}(\mathrm{EM} 4, \mathrm{EM} 11, \mathrm{EM} 14$ and EM24)showed EE of $77.1 \%, 77.1 \%, 77 \%, 77.2 \%$ respectively. There was a continuous increase in EE from levels $100 \mathrm{mg}$ to $400 \mathrm{mg}$ i. e, $74 \%$ to $77 \%$. From the above data, it could be concluded that there was the progressive influence of increasing concentration of lecithin on EE of obtained Ethosomes i. e, the more the concentration of lecithin, the more will be the \%EE.

\section{Effect of penetration enhancers and lecithin on \%EE}

When comparing $\mathrm{X} 1, \mathrm{X} 2$ and $\mathrm{X} 3$ independent variables on $\mathrm{EE}, \mathrm{X} 1$ at a higher level than X2 at a lower level with X3 at level $400 \mathrm{mg}$ showed elevated EE i.e, $77.2 \%$. So we can say that increase concentration of ethanol along with lecithin also influences EE.

The derived polynomial equation for the considered factor $\left(\mathrm{Y}_{1}\right)$ that clarifies its relation with all responses is given as:

$\mathrm{Y} 1=76.50+0.1400 \quad \mathrm{X}_{1}-0.0036 \quad \mathrm{X}_{2}+1.02 \quad \mathrm{X}_{3}-0.0333 \quad \mathrm{X}_{1} \mathrm{X}_{2}-0.0150$ $\mathrm{X}_{1} \mathrm{X}_{3}+0.0429 \mathrm{X}_{2} \mathrm{X}_{3}-0.4554 \mathrm{X}_{3}^{2}$

It was noticed that all the responses $\mathrm{X}_{1}, \mathrm{X} 2$, and $\mathrm{X}_{3}$ provided significant model terms. And the adjusted $\mathrm{R} 2$ signified value of 0.8089 was related to the predicted R2 $(0.7532)$, which probably asserts the linearity of the data as further confirmed in fig. 3 . Besides, the value of $\mathrm{R} 2$ was recorded (0.8671) and the required adequate precision of 11.8571 from table 2 , indicates the potential of the model to direct the design space. Fig. 1A, 1B, 2A, 2B displayed the $2 \mathrm{D}$ contour and $3 \mathrm{D}$ response surface plot of $\mathrm{EE}$ that emphasized the positive impact of variable $\mathrm{Y}_{1}$. 
N. M. et al.

Table 3: ANOVA for quadratic model for $\% \mathrm{EE}$

\begin{tabular}{|c|c|c|c|c|c|}
\hline Source & Sum of squares & DF & Mean square & F-value & P-value \\
\hline Model & 12.27 & 7 & 1.75 & 14.91 & $<0.0001$ significant \\
\hline A-Ethanol & 0.4573 & 1 & 0.4573 & 3.89 & 0.0662 \\
\hline B-IPA & 0.0003 & 1 & 0.0003 & 0.0025 & 0.9605 \\
\hline C-Lecithin & 10.88 & 1 & 10.88 & 92.52 & $<0.0001$ \\
\hline $\mathrm{AB}$ & 0.0267 & 1 & 0.0267 & 0.2268 & 0.6404 \\
\hline $\mathrm{AC}$ & 0.0023 & 1 & 0.0023 & 0.0198 & 0.8897 \\
\hline BC & 0.0190 & 1 & 0.0190 & 0.1620 & 0.6927 \\
\hline $\mathrm{A}^{2}$ & 0.0000 & 0 & & & \\
\hline $\mathrm{B}^{2}$ & 0.0000 & 0 & & & \\
\hline $\mathrm{C}^{2}$ & 0.8601 & 1 & 0.8601 & 7.31 & 0.0156 \\
\hline
\end{tabular}

$\mathrm{A}, \mathrm{B}$ and $\mathrm{C}=$ main factors., $\mathrm{AB}, \mathrm{AC}$ and $\mathrm{BC}=$ Interaction between main factors., $\mathrm{DF}=$ Degree of freedom.
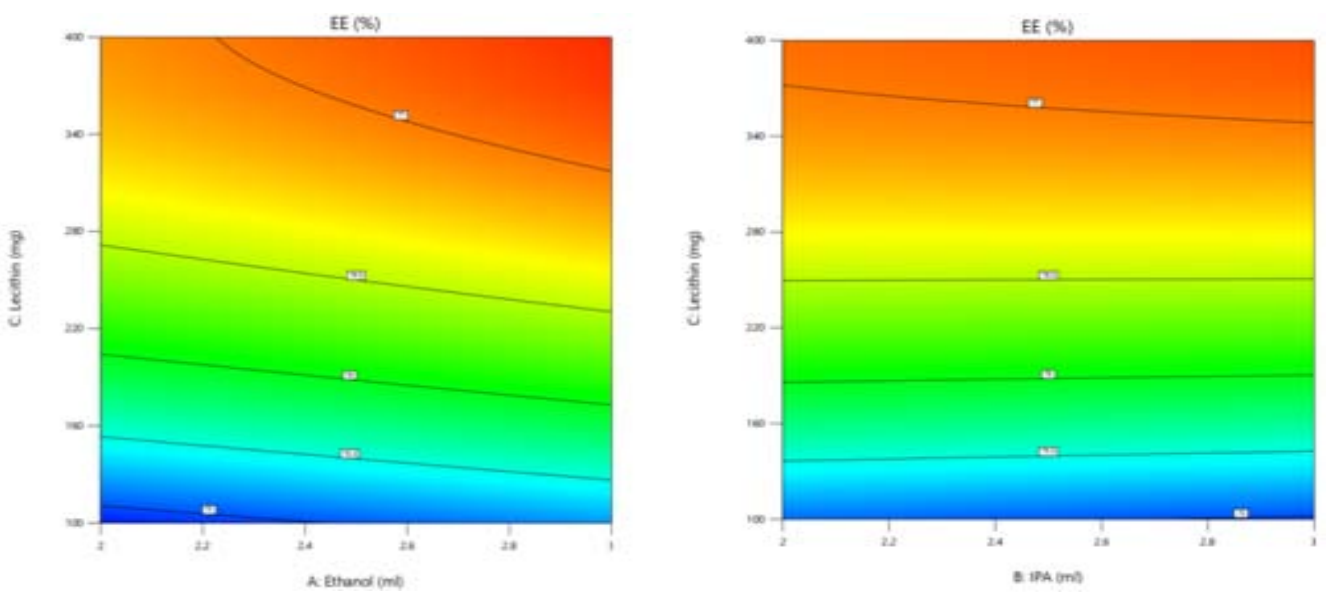

Fig. 1(A):2D contour graph of $(X 1)$ and $(X 3)$ on \%DR( $\left.Y_{1}\right),(B): 2 D$ contour graph of $(X 2)$ and $(X 3)$ on \%DR(Y)
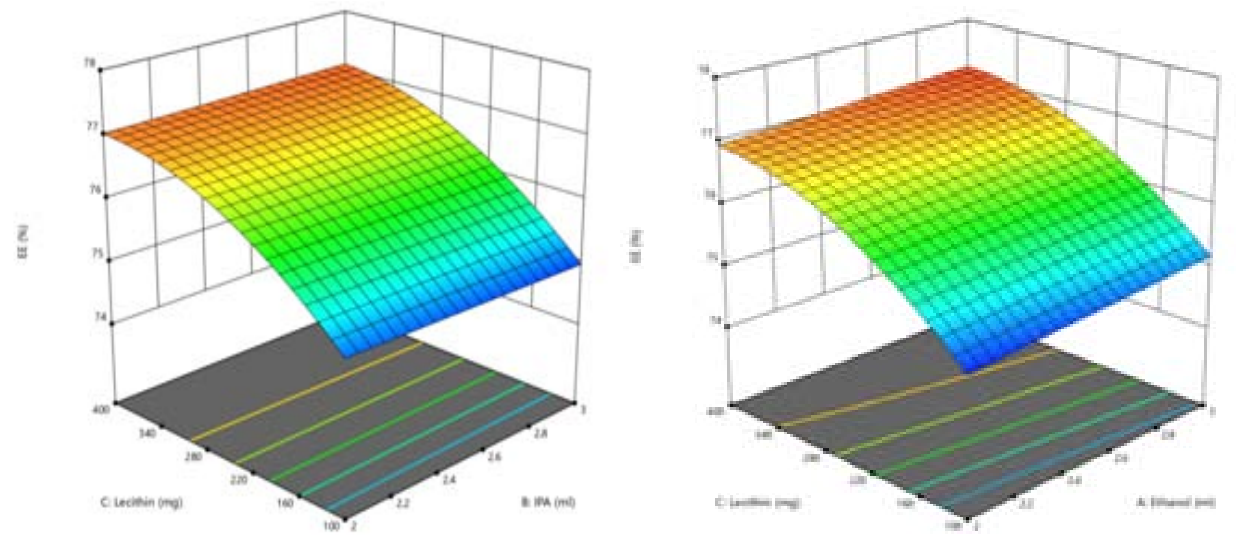

Fig. 2(A): 3D response surface plot(X2) and (X3) on \%DR(Y1), (B):3D response surface plot(X3) and (X1) on \%DR(Y1)

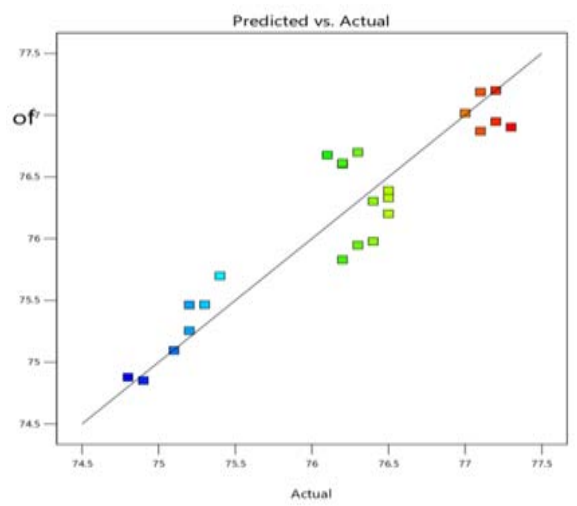

Fig. 3: Linear correlation plot between actual and predicted values for response (Y1) 


\section{In vitro drug release}

\section{Effect of permeation enhancers and lecithin on DR}

More drug release was shown with formulations EM6, EM12, and EM21 with the same levels of Independent variables X1, X2, and levels $100 \mathrm{mg}, 150 \mathrm{mg}$ of Independent variable X3. So, we can say that the same concentration of penetration enhancer and lower concentrations of lecithin enhance the drug release of ethosomes.

The derived polynomial equation for the considered factor $\left(\mathrm{Y}_{2}\right)$ that clarifies its relation with all responses is given as:

\section{$\mathrm{Y} 2=95.75-0.28 \mathrm{X}_{1}-0.23 \mathrm{X}_{2}-2.65 \mathrm{X}_{3}+0.01 \mathrm{X}_{1} \mathrm{X}_{2}+0.013 \mathrm{X}_{1} \mathrm{X}_{3}+0.05 \mathrm{X}_{2} \mathrm{X}_{3}-2.06 \mathrm{X}_{3}{ }^{2}$}

It was noticed that all the responses $X_{1}, X_{2}$, and $X_{3}$ provided significant model terms. And the adjusted R 2 signified value of 0.9168 was related to the predicted R2 $(0.8385)$, which probably asserts the linearity of the data as further confirmed in fig. 6 . Besides, the value of R 2 was recorded (0.9421) and the required adequate precision of 18.9635 from table 2 , indicates the potential of the model to direct the design space. Fig. 4A,4B,5A,5B displayed the 2D contour and the 3D response surface plot emphasized the positive impact of variable $\mathrm{Y}_{2}$.

Table 4: ANOVA for the quadratic model for \%DR

\begin{tabular}{|c|c|c|c|c|c|}
\hline Source & Sum of squares & DF & Mean square & F-value & p-value \\
\hline Model & 93.85 & 7 & 13.41 & 37.21 & $<0.0001$ (significant) \\
\hline A-Ethanol & 1.84 & 1 & 1.84 & 5.11 & 0.0380 \\
\hline B-IPA & 1.29 & 1 & 1.29 & 3.57 & 0.0771 \\
\hline C-Lecithin & 72.94 & 1 & 72.94 & 202.42 & $<0.0001$ \\
\hline $\mathrm{AB}$ & 0.0081 & 1 & 0.0081 & 0.0224 & 0.8829 \\
\hline $\mathrm{AC}$ & 0.0019 & 1 & 0.0019 & 0.0052 & 0.9432 \\
\hline $\mathrm{BC}$ & 0.0307 & 1 & 0.0307 & 0.0853 & 0.7740 \\
\hline$A^{2}$ & 0.0000 & 0 & & & \\
\hline $\mathrm{B}^{2}$ & 0.0000 & 0 & & & \\
\hline $\mathrm{C}^{2}$ & 17.56 & 1 & 17.56 & 48.74 & $<0.0001$ \\
\hline
\end{tabular}

$\mathrm{A}, \mathrm{B}$ and $\mathrm{C}=$ main factors $\mathrm{AB}, \mathrm{AC}$ and $\mathrm{BC}=$ Interaction between main factors, $\mathrm{DF}=$ Degree of freedom.
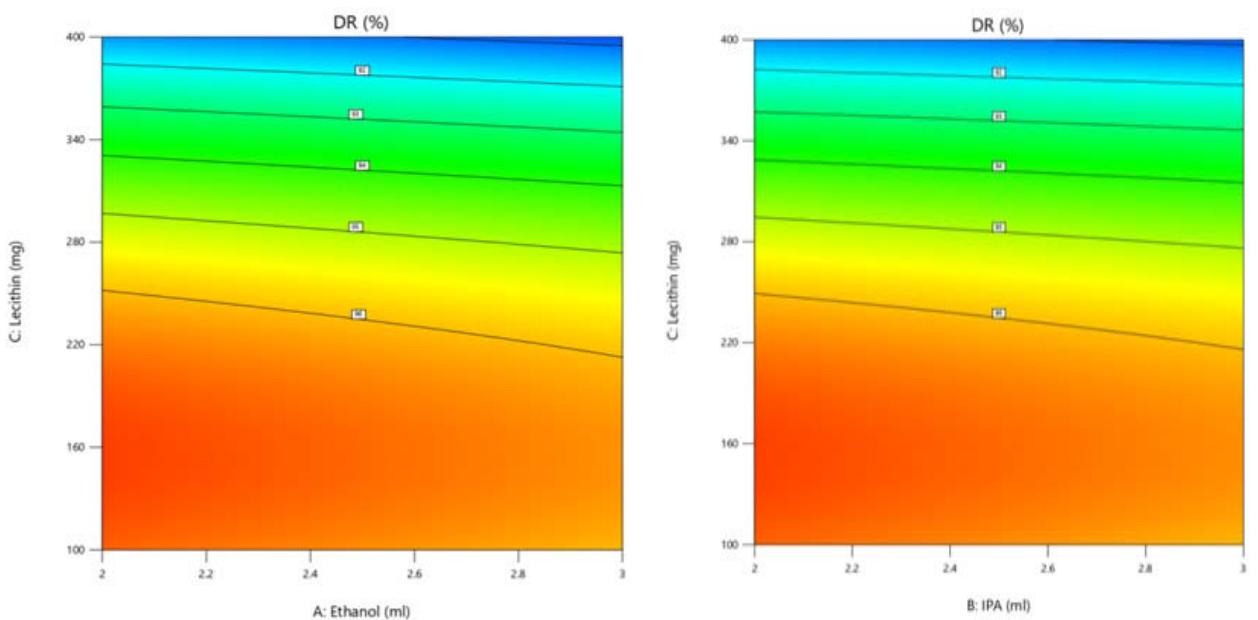

Fig. 4(A):2D contour graph of (X1) and (X3) on \%DR( $\left.\mathrm{Y}_{2}\right),(\mathrm{B}): 2 \mathrm{D}$ contour graph of $(\mathrm{X} 2)$ and $(\mathrm{X} 3)$ on \%DR( $\left.\mathrm{Y}_{2}\right)$

3D Surface

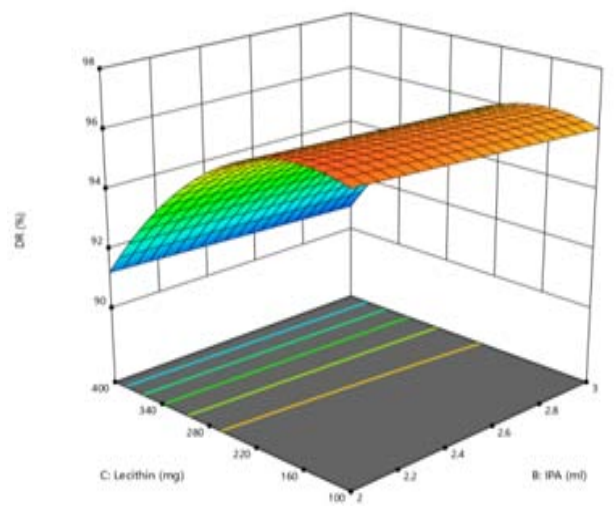

30 Surface

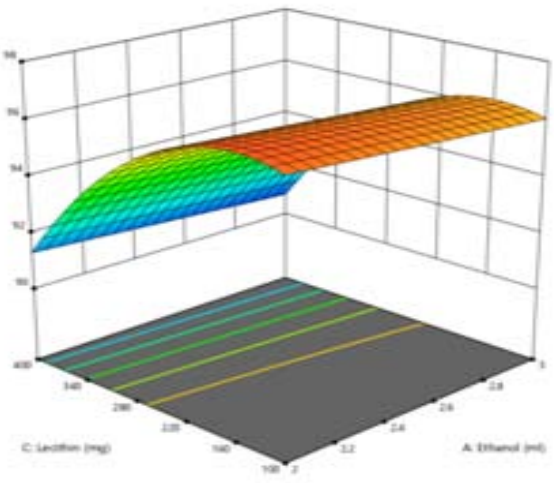

Fig. 5(A): 3D response surface plot(X2) and (X3) on \%DR(Y2), (B):3D response surface plot(X3) and (X1) on \%DR(Y2) 


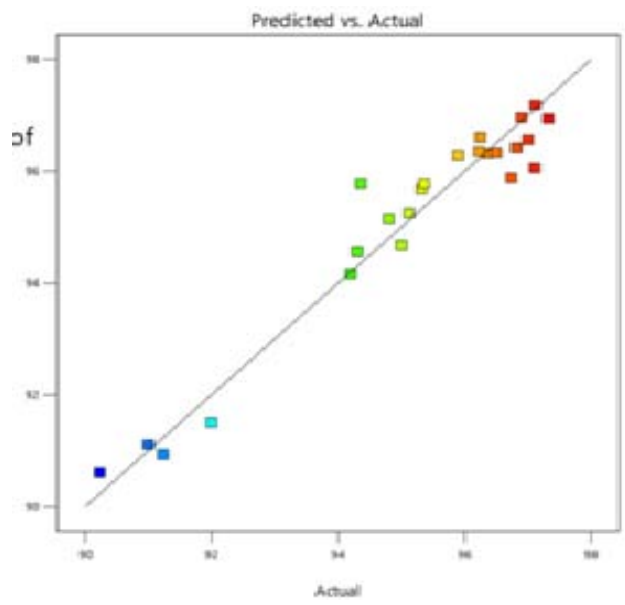

Fig. 6: linear correlation plot between actual and predicted values for response (Y2)

Several studies revealed that the optimized lecithin concentration, ethanol concentration, and Isopropyl alcohol concentration play a notable role in the entrapment of the drug and drug release of the dispersion system [15].

\section{Optical microscope observation}

The ethosomal dispersion was spread on the glass slide using a glass rod. The formation of multilamellar vesicles was confirmed by examining the ethosomal suspension under an optical microscope with a magnification of 40X and 10X. Photographs of vesicles were taken using a Samsung galaxy camera. One of the studies showed that on increasing the ethanol concentration from 10 to $30 \% \mathrm{v} / \mathrm{v}$, the turbidity increases, which is significant in this study [19].

\section{Spreadability}

Spreadability for the optimized formulation was found to be 10.05 gm. cm/sec. From the result, we can say that excellent spreadability was seen in the study [16].

\section{In vitro comparative study for optimized gel using the marketed} formulation

The in vitro drug release studies of optimized ethosomal gel and marketed microgel cream were studied using Franz diffusion cell.
EM6 and EG was found to be the best as it was able to sustain the release for about $8 \mathrm{~h}$ with a cumulative percentage release of about $97.32 \%$ and $79.13 \%$, respectively, when compared with marketed formulation (Micogel cream).

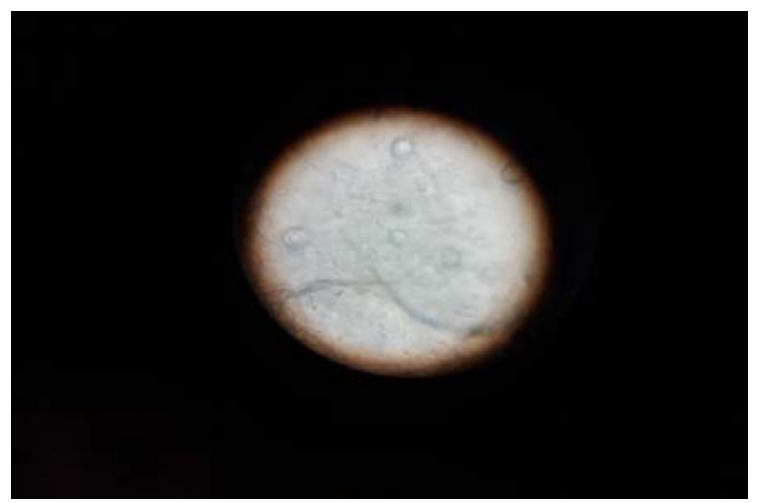

Fig. 7: Microscopic image of optimized formulation of ethosomes

Table 5: Stability studies of ethosomal gel

\begin{tabular}{|c|c|c|c|c|}
\hline Parameters & Initial & $1^{\text {stmo }}$ & $2^{\text {nd }} \mathrm{mo}$ & $3^{\text {rdmo }}$ \\
\hline pH value* & $6.94 \pm 0.19$ & $7.1 \pm 0.24$ & $7.1 \pm 0.12$ & $7.2 \pm 0.5$ \\
\hline Drug content $(\%)^{*}$ & $93.66 \pm 0.16$ & $92.1 \pm 0.21$ & $91.5 \pm 0.25$ & $91.0 \pm 0.2$ \\
\hline Viscosity (cps)* at $50 \mathrm{rpm}$ & $5451 \pm 3.1$ & $5291 \pm 4.06$ & $5249 \pm 2.5$ & $4981 \pm 3.0$ \\
\hline
\end{tabular}

${ }^{*}$ All values are expressed as mean $\pm \mathrm{SD}, \mathrm{n}=3$

Stability study of the optimized ethosomal gel formulation was conducted at temperature $40^{\circ} \mathrm{C} \pm 2^{\circ} \mathrm{C}$ for a period of $3 \mathrm{mo}$. There was an insignificant difference in all the parameters and as per the results to achieve the best stability, ethosomal suspension should be stored in a refrigerator before converting to ethosomal gel [15].

\section{CONCLUSION}

The study revealed that the development of ethosomal preparations is a suitable carrier for drug delivery of Miconazole nitrate. The optimization of ethosomes was done by Factorial design and was evaluated for \%EE and \%DR. The effect of independent variables on the responses was studied. Based on $\% \mathrm{EE}$ and $\% \mathrm{DR}$, formulations were analyzed and optimized. So that formulated ethosomal suspension can be used for the preparation of antifungal gels, creams, ointments for sustained release.

\section{FUNDING}

Nil

\section{AUTHORS CONTRIBUTIONS}

All authors have contributed equally.

\section{CONFLICT OF INTERESTS}

\section{Declared none}

\section{REFERENCES}

1. Anoop K, Rakesh R. Formulation and optimization of nanosized ethosomes for enhanced transdermal delivery of cromolyn sodium. J Pharm Bioall Sci. 2012;4(4):333. doi: 10.4103/0975-7406.103274. 
2. Jain S, Tiwary AK, Sapra B, Jain NK. Formulation and evaluation of ethosomes for transdermal delivery of lamivudine. AAPS PharmSciTech. 2007;8(4):E111. doi: 10.1208/pt0804111, PMID 18181532.

3. Elsayed MM, Abdallah OY, Naggar VF, Khalafallah NM. Lipid vesicles for skin delivery of drugs: reviewing three decades of research. Int J Pharm. 2007;332(1-2):1-16. doi: 10.1016/ j.ijpharm.2006.12.005, PMID 17222523.

4. Chakraborty T, Saini V, Sharma S, Kaur B, Dhingra G. Antifungal gel: for different routes of administration and different drug delivery system. Int J Biopharm. 2014;5:230-40.

5. Tanriverdi ST, Ozer 0 . Novel topical formulations of terbinafine- $\mathrm{HCl}$ for treatment of onychomycosis. Eur J Pharm Sci. 2013;48(4-5):628-36. doi: 10.1016/j.ejps.2012.12.014, PMID 23295582.

6. Mallikarjun PN, Anusha S, Sai Nandini V, Rama Rao B, Kamala Kumari PV, Srinivasa Rao Y. Hydrogel: responsive structures for drug delivery. Int J Appl Pharm. 2021;13:65-76.

7. Zhou Y, Wei Y, Liu H, Zhang G, Wu XA. Preparation and in vitro evaluation of ethosomal total alkaloids of Sophora alopecuroides loaded by a transmembrane pH-gradient method. AAPS PharmSciTech. 2010;11(3):1350-8. doi: 10.1208/s12249-010-9509-6, PMID 20740333.

8. Kumar L, Verma S, Singh K, Prasad DN, Jain AK. Ethanol-based vesicular carriers in transdermal drug delivery: nanoethosomes and transethosomes in focus. NanoWorld J. 2016;2:41-51.

9. Bhattacharyya I, Bose S, Pramanik T, Dey S. Extraction of lecithin from egg yolk and its characterization. Asian J Pharm Anal Med Chem. 2018;6:145-8.

10. Attia KA, Nassar MW, El-Dosoky MM, Abdul-Kareem RF. Quantitative analysis of miconazole nitrate in a binary mixture with betamethasone valerate in bulk powder and cream formulation by various spectrophotometric techniques. World J Pharm Res. 2016;5:173-90.

11. Abdulbaqi IM, Darwis Y, Khan NA, Assi RA, Khan AA. Ethosomal nanocarriers: the impact of constituents and formulation techniques on ethosomal properties, in vivo studies, and clinical trials. Int J Nanomed. 2016;11:2279-304. doi: 10.2147/ IJN.S105016, PMID 27307730.

12. Sujatha S, Sowmya G, Chaitanya M, Reddy VK, Monica M, Kumar KK, Sujatha S. Preparation, characterization and evaluation of finasteride ethosomes. Int J Drug Deliv Technol. 2016;8:1-11.

13. Begum RU, Sridhar Babu R, Kishor DV, Begum NU. Formulation and in vitro evaluation of ciclopirox ethosomal gel. Drug Dev Deliv. 2019;2(2):8-16.

14. Hariharanb S, Justinc A. Topical delivery of drugs using ethosomes: a review. Indian Drugs. 2019;56:7.

15. Wagh MP, Mutha (Bora) SS. Development and optimization of rizatriptan benzoate ethosomes. Int J Appl Pharm. 2018;10(2):83-90. doi: 10.22159/ijap.2018v10i2.24354.

16. Shukla KV, Sharma A, Yadav M. Formulation development and evaluation of ethosomal gel of acyclovir for the treatment of herpes zoster. J Drug Deliv Ther. 2019;9:664-8.

17. Ismail TA, Shehata TM, Mohamed DI, Elsewedy HS, Soliman WE. Quality by design for development, optimization and characterization of brucine ethosomal gel for skin cancer delivery. Molecules. 2021 January;26(11):3454. doi: 10.3390/molecules26113454, PMID 34200144.

18. Nimisha SK, Singh AK. Formulation and evaluation of sea buckthorn leaf extract loaded ethosomal gel. Asian J Pharm Clin Res. 2015;8(5):309-12.

19. Lamsal R, Geethalakshmi A, Gubbala S. Formulation and evaluation of gliclazide ethosomes as a novel drug carrier. Int J Pharm Sci Res. 2015 May 1;6(5):2072. 